\title{
Design and Realization of City Tourism Interest Geographic Information Data Collection System
}

\author{
ZHOU Xiao $^{a}$, ZHU Shuai $^{b}$, YAO Lan ${ }^{c}$, LI Xu $^{\mathrm{d}}$, ZHANG Haoyi $^{\mathrm{e}}, \mathrm{HE} \mathrm{Wei}^{f}$
}

Information Engineering University, No.62 Kexue Avenue, High-tech Zone, Zhengzhou, China

azhou_laoge@163.com, bzbgzgy@163.com, '13243682310@163.com,

d909009935@qq.com, e zhanghaoyiwell@qq.com, ${ }^{\mathrm{d}}$ maple0081@aliyun.com

Keywords: city tourism; tourism interest; geographic information; data collection; system design

Abstract. City tourism contains plentiful data information, but not all the information is interested by tourists. Relying on tourists' interests, this paper designs and develops city tourism interest geographic information data collection system. Take Zhengzhou urban sight spots as an example to collection data information, under certain software and hardware condition, each function module is developed. Through two tests, the feasibility and usability are verified.

\section{Introduction}

Currently, city tourism is a hot mode on the tourism route. Tourism relies on geographic information, including sight spot information, traffic information, weather information and service information. Not all the information contained in a city is interested by tourists, especially when the traveling time is limited, tourists may be interested in merely one or some tourism information[1]. Providing various kinds of tourism information for tourists, collecting tourists' interested information through informationalized platform can provide tourism geographic information with strong pertinence for tourists and avoid redundant information disturbing tourists' subjective judgment[2,3]. On the aspect of collecting data, city tourism interest geographic information data collection system is developed and tourism based on interest is put forward. Through experiment tests, it proves that this system can realize functions of interest information collection, interest data output, etc. and has good feasibility and usability.

\section{City Tourism Geographic Information Data Acquisition}

City tourism geographic information data contains information of sight spot attribute, sight spot spatial, traffic attribute, traffic spatial, weather, service, etc. Spot attribute information contains name, star level, introduction, special items, fees, etc. Spatial information is sight spot location. Traffic attribute information contains bus, subway, taxi, stations, route, fee, etc. and its spatial information is location. Weather information contains each municipal district and each time frame's weather. Service information contains other relative service[4].

Tourism geographic information data is classified. Information of sight spot attribute, sight spot spatial, traffic attribute, traffic spatial, weather, service are labeled as A, B, C, D, E and F. According to category, sight attribute information can be divided into $A_{1}$ : Park and green field, $A_{2}$ : Playground yard, $A_{3}$ : Venue and $A_{4}$ : Shopping and its spatial information can be divided into $B_{1}$ : East-west roads and $\mathrm{B}_{2}$ : North-south roads. Traffic attribute information contains $\mathrm{C}_{1}$ : Bus, $\mathrm{C}_{2}$ : subway and $\mathrm{C}_{3}$ : Taxi and its spatial information contains $\mathrm{D}_{1}$ : Bus station and route, $\mathrm{D}_{2}$ : Subway station and route and $\mathrm{D}_{3}$ : Taxi docking station. Weather information contains $\mathrm{E}_{1}$ : District weather, $\mathrm{E}_{2}$ : Time frame weather and $\mathrm{E}_{3}$ : Tourism index. Service information contains $\mathrm{F}_{1}$ : Medical treatment, $\mathrm{F}_{2}$ : Finance and post, $\mathrm{F}_{3}$ : Gas station and $\mathrm{F}_{4}$ : Hotel and restaurant. Each category contains several sub-classes[5].

$A=\left\{A_{1}\right.$ : Park and green field, $A_{2}$ : Playground yard, $A_{3}$ : Venue, $A_{4}$ : Shopping $\}$;

$\mathrm{B}=\left\{\mathrm{B}_{1}\right.$ : East-west roads, $\mathrm{B}_{2}$ : North-south roads $\}$;

$\mathrm{C}=\left\{\mathrm{C}_{1}\right.$ : Bus, $\mathrm{C}_{2}$ : subway, $\mathrm{C}_{3}$ : Taxi $\}$; 
$\mathrm{D}=\left\{\mathrm{D}_{1}\right.$ : Bus station and route, $\mathrm{D}_{2}$ : Subway station and route, $\mathrm{D}_{3}$ : Taxi docking station $\}$;

$\mathrm{E}=\left\{\mathrm{E}_{1}\right.$ : District weather, $\mathrm{E}_{2}$ : Time frame weather, $\mathrm{E}_{3}$ : Tourism index $\}$;

$\mathrm{F}=\left\{\mathrm{F}_{1}\right.$ : Medical treatment, $\mathrm{F}_{2}$ : Finance and post, $\mathrm{F}_{3}$ : Gas station, $\mathrm{F}_{4}$ : Hotel and restaurant $\}$.

\section{System Design}

System's main function is collecting sight spots selected by tourists relying on interest and obtaining related data information encapsulated in the system automatically. Data collection method is self-selecting and input by Internet interface. Relying on data categories, tourist interest collection modules are designed and they can be used to display tourism interest data information selected by tourists. Selected data information is transmitted to server-side terminal by net layer. Server-side terminal stores, analyzes and processes data information and provides tourism information display, map service and route programming service, etc.

System Developing Environment. VC++ 6.0 programming environment as well as SQL Server database and MapGIS software are used. System developing relates to attribute data and spatial data. Many interfaces are designed to invoke data stored in SQL Server database.

Hardware Environment. System developing uses one server DELL PowerEdge 12G R720 with 12 G computer memory, equipped with large capacity hard disk 500 G. Output device is Canon iP2780 printer.

Software Environment. Operating system is Windows XP. Programming environment is VC++ 6.0. Database is SQL Server 2008 database. Basic map charting tool is MapGIS software.

System Function Interface Design. The data resource of the system is Zhengzhou urban sight spots. Sight spot information collection module, spatial information collection module, traffic information module, weather information collection module and information management module are designed relying on system data structure. Sight spot information collection module is used to collect interest sight spots. Spatial information collection module is used to collect spatial information. Traffic information module is used to collect traffic information needed by tourists. Weather information collection module is used to collect weather information concerned by tourists. Information management module is used to display, store and manage data information. Fig.1 shows the designed each function module.

Weather Information Collection Module. Tourists can choose any Zhengzhou district's any time frame's weather through this module, for instance, “Zhongyuan district, 10-12clock", "Erqi district, 14-15clock”. Selected weather information is stored in background database.

Sight Spot Information Collection Module. Tourists can choose destination sight spots through this module, after which, all the attribute information and spatial information are stored in background database.

Traffic Information Collection Module. Tourists can choose bus station, subway station, bus route, subway route, etc. through this module. For tourists' convenience, railway information and flight information are also designed in the module.

Information Confirmation Module. Information confirmation module is used to confirm selected information by tourists and add, delete, empty, sequence or print the information.

Data Information Management Module. Data information management is used to store and manage the selected information.

Spatial Information Collection Module. Besides sight and traffic spatial information, tourists can use this module to select and add other road information. 


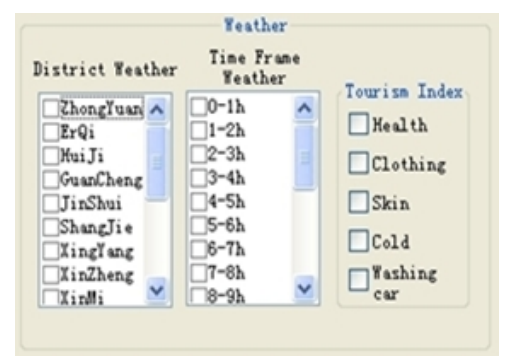

(1) Weather information collection module

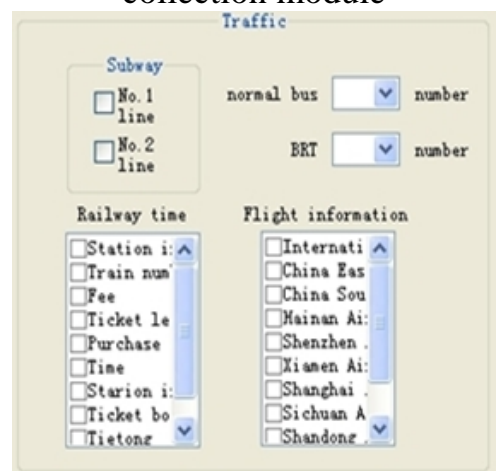

(3) Traffic information module

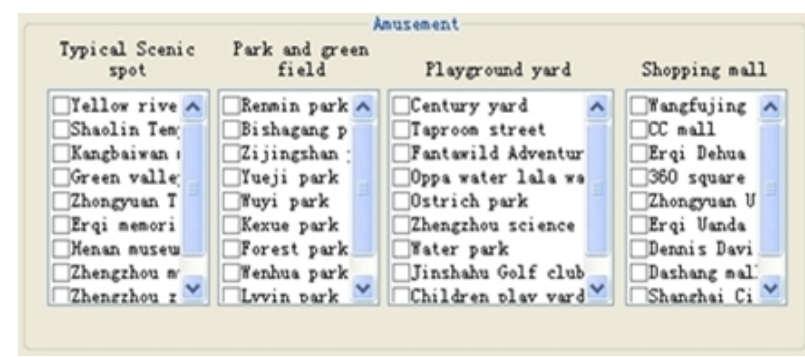

(2) Scenic spot information collection module

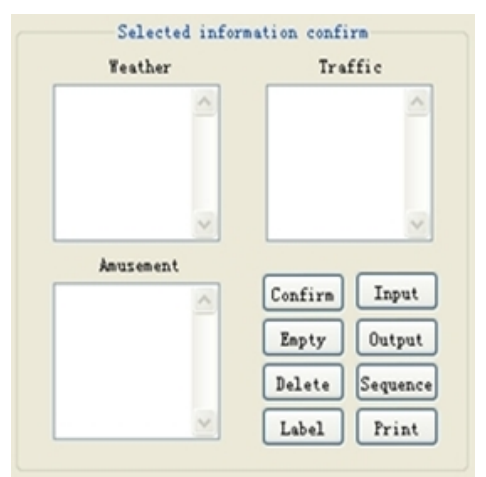

(4) Information confirmation module

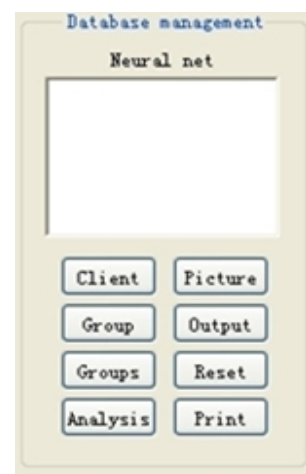

(5) Data information management module

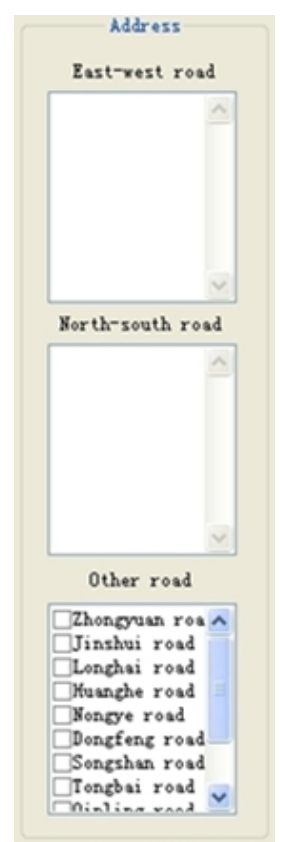

(6) Spatial information collection module

Fig.1 Function modules of city tourism interest geographic information data collection system

\section{System Function Tests}

Two tests are carried out to test the developed city tourism interest geographic information data collection system.

Test One. Tourism information collection and query function is tested.

A sample tourist chooses "Zhongyuan district, 10-11clock weather", "Clothing index" and "Washing car index". He also chooses "NO.216 bus" and "NO.1 subway" traffic information. After confirming information, system displays all the information as Fig.2 shows".

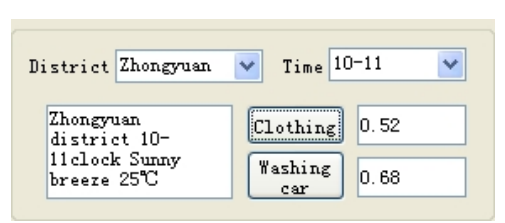

(1) Weather information

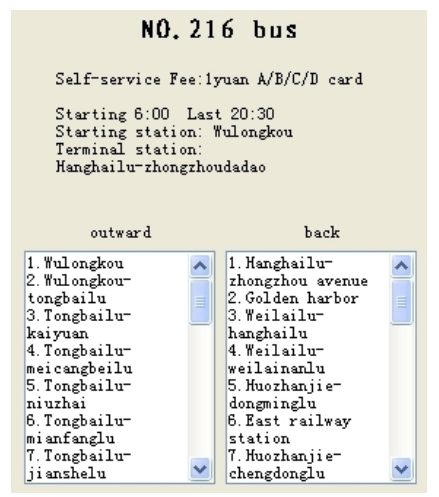

(2) Bus information

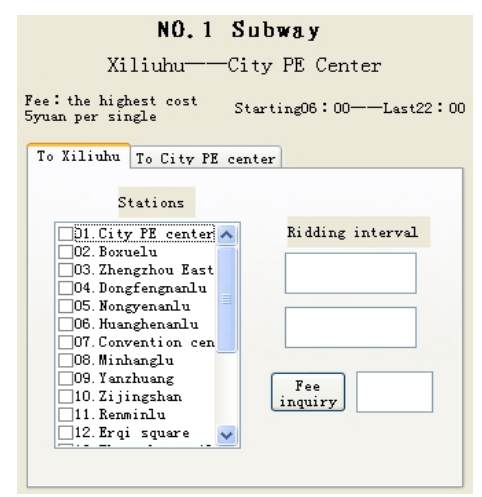

(3) Subway information

Fig.2 Tourism information collection and query

Test Two. Map output and route programming function is tested.

The sample tourist chooses three sight spots of “(1) Zhongyuan Uanda”, “(2) Erqi Dehua” and “(3) Century yard”. After confirming selected information, data information is uploaded to server-side terminal. Server-side terminal automatically generates tourism map relying on sight spot information and stresses roads around the sight spots. According to the selected sight spots, system automatically programs three optimal routes. They are (1) (1) $\rightarrow$ (2) $\rightarrow$ (3), (2) (3) $\rightarrow$ (2) $\rightarrow$ (1) and (3) (1) $\rightarrow$ (3) $\rightarrow$ (2). Priority reduces along the arrows. The output map and routes are shown in Fig.3. 


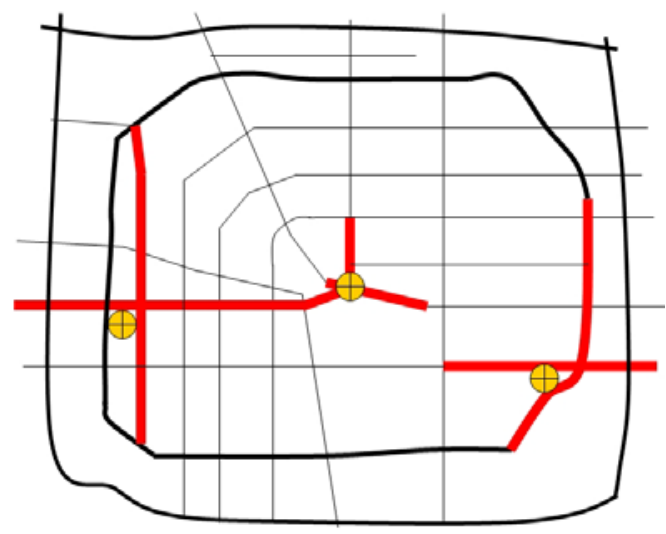

(1) Generated tourism information map

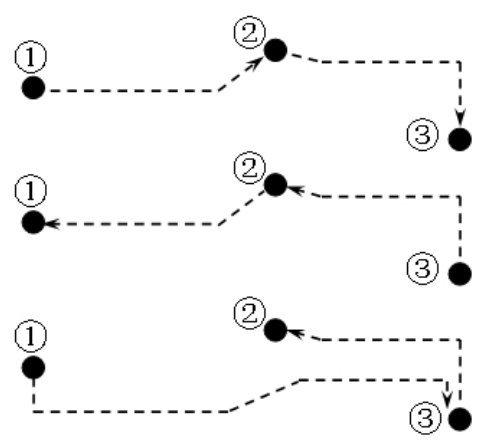

(2) Automatically programmed tourism routes

Fig.3 Automatically generated tourism information map and tourism routes

Test one and test two illustrate that the system designed in this paper can realize tourism data information collection and visualizes tourists' interest. By collecting, transmitting and processing tourism data information, system outputs tourists' needed information and generates tourism information map automatically for tourists. Meanwhile, system can automatically program optimal tourism routes for tourists relying on the selected sight spots.

\section{Conclusions}

In this paper, city tourism interest geographic information data collection system is designed and developed according to tourists' interests. This system can realize sight spot self-selecting and output tourists' needed tourism information through storing, transmitting and processing. Meanwhile, it can visualize tourism information to generate tourism information map and automatically program optimal tourism routes for tourists to refer to. Two tests illustrate that the system operates steadily. Its function is thorough with strong feasibility and usability.

\section{Acknowledgements}

This work was complished by my research group. All of my team members took part in the experiment, programming, system designing, figures charting and paper writing. Here I appreciate their support and talent work very much.

\section{References}

[1] Nicolau J L, Ma's F J. The influence of distance and prices on the choice of tourist destinations: the moderating role of motivations. Tourism Management, 2006, 27, p.982-996.

[2] Manuel V, Robertico R C( 2000) . Evaluation of demand US tourists to Aruba. Annals of Tourism Research'27(4), p.946-963.

[3] Vansteenwegen P, Van Oudheusden D( 2007). The mobile tourist guide: an OR opportunity. OR Insight, 20(3) , p.21-27.

[4] Bosque I R, Martin H S. Tourist satisfaction: A cognitive affective model. Annals of Tourism Research, 2008, 35( 2) , p.551-573.

[5] Nicolau J L, Ma’s F J, Sequential choice behavior: Going on vacation and type of destination. Tourism Management, 2008, 29:1023-1034. 